\title{
Non-rainfall Moisture: A Key Driver of Microbial Respiration from Standing Litter in Arid, Semiarid, and Mesic Grasslands
}

\author{
Sarah Evans, ${ }^{1,6 *}$ Katherine E. O. Todd-Brown, ${ }^{2,3,4}$ Kathryn Jacobson, ${ }^{5}$ \\ and Peter Jacobson ${ }^{5}$
}

\begin{abstract}
${ }^{1}$ Kellogg Biological Station, Ecology, Evolutionary Biology, and Behavior Program, Department of Integrative Biology, Department of Microbiology and Molecular Genetics, Michigan State University, Hickory Corners, Michigan, USA; ${ }^{2}$ Pacific Northwest National Laboratory, Richland, Washington, USA; ${ }^{3}$ Wilfred Laurier University, Waterloo, Ontario, Canada; ${ }^{4}$ Engineering School of Sustainable Infrastructure and Environment, University of Florida, Gainesville, Florida, USA; ${ }^{5}$ Department of Biology, Grinnell College, Grinnell, Iowa, USA; ${ }^{6}$ Natural Resource Ecology Laboratory, Colorado State University, Campus Delivery 1499, Fort Collins, Colorado 80523,
\end{abstract} USA

\begin{abstract}
Models assume that rainfall is the major moisture source driving decomposition. Non-rainfall moisture (NRM: high humidity, dew, and fog) can also induce standing litter decomposition, but there have been few measurements of NRM-mediated decomposition across sites and no efforts to extrapolate the contribution of NRM to larger scales to assess whether this mechanism can improve model predictions. Here, we show that NRM is an important, year-round source of moisture in grassland sites with contrasting moisture regimes using field measurements and modeling. We first characterized NRM frequency and measured NRMmediated decomposition at two sites in the Namib Desert, Namibia (hyper-arid desert), and at one site in Iowa, USA (tallgrass prairie). NRM was frequent
\end{abstract}

Received 15 July 2019; accepted 26 October 2019; published online 2 December 2019

Electronic supplementary material: The online version of this article (https://doi.org/10.1007/s10021-019-00461-y) contains supplementary material, which is available to authorized users.

Author's Contributions KJ and PJ conceived the empirical study and collected data with assistance from SE. KTB and SE conceived and performed the meteorological analysis and modeling. SE was lead author, but all authors contributed to writing the paper.

*Corresponding author; e-mail: evanssa6@msu.edu at all sites (85-99\% of hours that litter was likely to be wet were attributed to NRM) and tended to occur in cool, high-humidity periods for several hours or more at a time. NRM also resulted in $\mathrm{CO}_{2}$ release from microbes in standing litter at all sites when litter became sufficiently wet $>5 \%$ gravimetric moisture for fine litter and $>13 \%$ for coarse), and significantly contributed to mass loss, particularly in the western Namib site that received almost no rain. When we modeled annual mass loss induced by NRM and rain and extrapolated our characterization of NRM decomposition to a final semiarid site (Sevilleta, New Mexico), we found that models driven by rainfall alone underestimated mass loss, while including NRM resulted in estimates within the range of observed mass loss. Together these findings suggest that NRM is an important missing component in quantitative and conceptual models of litter decomposition, but there is nuance involved in modeling NRM at larger scales. Specifically, temperature and physical features of the substrate emerge as factors that affect the microbial response to litter wetting under NRM in our sites, and require further study. Hourly humidity can provide an adequate proxy of NRM frequency, but site-specific calibration with litter 
wetness is needed to accurately attribute decomposition to periods when NRM wets litter. Greater recognition of NRM-driven decomposition and its interaction with other processes like photodegradation is needed, especially since fog, dew, and humidity are likely to shift under future climates.

Key words: fog; dew; non-rainfall moisture (NRM); standing litter; microbial decomposition; drylands; semiarid; mesic; modeling.

\section{HighLights}

- Non-rainfall moisture (NRM; humidity, fog, dew) induces decomposition in grasslands.

- NRM decomposition depends on substrate type and occurs at colder times than rain.

- Including NRM (instead of rain alone) improved predictions of litter decomposition.

\section{INTRODUCTION}

Decomposition of plant litter and soil organic matter adds more carbon dioxide $\left(\mathrm{CO}_{2}\right)$ to the atmosphere than fossil fuel use (Schlesinger and Andrews 2000). Thus, relatively small changes in decomposition will have large impacts on atmospheric $\mathrm{CO}_{2}$ concentrations and carbon-climate feedbacks. Despite this importance, our understanding of decomposition, and ability to predict how it will change under future climates, is limited. In particular, ecosystem models, most of which use rainfall and temperature as the major climatic drivers of decomposition, consistently underestimate litter decay rates in drylands (Whitford and others 1981; Throop and Archer 2009), suggesting that mechanisms relevant to decomposition in these areas are omitted. Indeed, recent studies show that previously unrecognized processes such as photodegradation and soil-litter mixing drive significant surface litter decomposition (Austin and Vivanco 2006; Gallo and others 2006; Throop and Archer 2009; Barnes and others 2011; King and others 2012; Baker and others 2015; Lin and others 2018).

An additional phenomenon that may explain underestimation of decomposition in drylands-and potentially other systems-is the stimulation of microbial decomposition by non-rainfall moisture (NRM), or fog, dew, and high humidity. In semiarid Mediterranean grasslands, Dirks and others (2010) estimated that decomposition in the absence of both rain and photodegradation accounted for an $18 \%$ reduction in litter mass, which constituted up to $50 \%$ of annual decomposition in this system. They did not directly measure the effect of NRM on decomposition but hypothesized that the decomposition they observed in rainless periods was driven by atmospheric water vapor. Gliksman and others (2017) quantified the influence of NRM-mediated decomposition (hereafter 'NRM decomposition') on mass loss at semiarid sites by manipulating microclimate and saw a significant decrease in mass loss in litter bags when NRM and UV were excluded. The role of NRM in decomposition may extend beyond water-limited areas as well (Newell and others 1985; Kuehn and others 2004). For instance in wetlands, Kuehn and others (2004) observed diel mineralization cycles of standing litter during rainless periods that corresponded with nightly dew formation, with $\mathrm{CO}_{2}$ flux rates comparable to that emitted from soils and sediments.

Despite accumulating evidence that attests to the potential importance of NRM as a driver of decomposition, there have been few attempts to generalize the processes that control NRM decomposition across biomes or scale NRM decomposition across space and time. Before NRM can be incorporated into conceptual and quantitative models, we need to know more about controls on NRM decomposition and the best approaches for characterizing NRM frequency and duration in different ecosystems. Studies examining mechanistic controls on NRM decomposition, many performed in the laboratory, have highlighted several underlying drivers of NRM decomposition. Dirks and others (2010) suggested that microbial activity drove litter decay in rainless periods because variation in mass loss and litter nitrogen was explained by litter water-vapor uptake. We showed that litter collected from the Namib Desert exhibited significant $\mathrm{CO}_{2}-\mathrm{C}$ flux rates under laboratory-simulated nighttime dew and fog (Jacobson and others 2015), beginning within 5 min after gravimetric moisture exceeded a critical threshold and lasting for $10 \mathrm{~h}$ (as long as litter was wet). We also found that substrate type may be an important control on NRM decomposition; short periods $(2 \mathrm{~h}$ ) of greater than $95 \%$ relative humidity $(\mathrm{RH})$ induced microbial respiration, but only in fine-textured litter (for example, grass leaves) and not in coarse tiller stems (Jacobson and others 2015). Further, litter position affects NRM decomposition-standing litter becomes wetter with nighttime humidity and has higher mass loss 
than surface litter (Almagro and others 2015; Wang and others 2017a; Gliksman and others 2018)-highlighting the importance of position on measurements of both NRM frequency (Sentelhas and others 2008) and litter decomposition.

In addition to increased mechanistic knowledge of NRM decomposition, studies of this phenomenon at regional and annual scales are also needed. Few attempts have been made to characterize NRM across biomes, and even fewer to extrapolate its contribution to heterotrophic respiration or annual mass loss. This is in contrast to the vast efforts made to monitor rainfall frequency and understand the effect of rainfall on soil moisture and soil respiration. Climatic variables that help predict occurrence of NRM, like diel RH and temperature, are different from those describing water from rainfall (McHugh and others 2015), and direct measurements of condensed water resulting from NRM such as leaf wetness sensor measurements are rarely included in standard meteorological measurements (Uclés and others 2016) or collected while measuring litter decomposition. Further, measurements of humidity are typically made at standard height of $1.5 \mathrm{~m}$, rather than at lower heights near standing litter, where RH may differ due to the influence of soil and vegetation on temperature and water availability (Ritter and others 2019).

We tested the overarching hypothesis that NRM is an important, year-round source of moisture in xeric and mesic grasslands by (1) offering a firsttime quantification of NRM's contribution to annual mass loss relative to rain, (2) describing the factors that control NRM decomposition, and the conditions under which it occurs, and (3) assessing the ability of different approaches to estimate NRM frequency and NRM decomposition.

We took a coupled empirical modeling approach to meet these goals. We first quantified NRM type, frequency, and duration, and measured microbial respiration $\left(\mathrm{CO}_{2}\right.$ flux $)$ and annual mass loss of standing litter under NRM at three grassland locations with different moisture regimes (a hyper-arid site in the western Namib Desert with high NRM; an arid site in the eastern Namib Desert with infrequent NRM; and a mesic site in an Iowan grassland with high rainfall and NRM). These empirical field measurements allowed us to assess the conditions under which NRM decomposition occurs, and develop predictive relationships between NRM meteorology and decomposition. Using this information, we modeled annual mass loss when excluding and including NRM (in addition to rain) at each site. We applied our model that extrapolated mass loss attributed to rain and NRM to an additional site, Sevilleta, New Mexico, to test the robustness of our estimate of NRM decomposition at a semiarid grassland.

\section{MethodS}

\section{Site Descriptions}

Our entire study (NRM characterization, $\mathrm{CO}_{2}-\mathrm{C}$ flux measurements, and modeling) included analysis efforts in three regions: the Namib Desert (Namibia), Iowa tallgrass prairie (USA) (Figure 1, Table 1), and a New Mexico semiarid grassland (USA) (Figure S1, Table 1). We took empirical measurements $\left(\mathrm{CO}_{2}-\mathrm{C}\right.$ flux and mass loss from litter, and direct measurement of NRM) at two sites in the Namib with contrasting moisture regimes, and one site in Iowa. We chose sites in the Namib (hyper-arid desert) because we have ongoing investigations of microbially-mediated surface litter decomposition here that are facilitated by existing meteorological infrastructure that monitors NRM. The mesic grassland site in Iowa (tall-grass prairie) was chosen because it provided an extreme contrast (across grasslands) to the hyper-arid Namib sites and because of its close proximity to one of our home institutions. We also analyzed data from a semiarid grassland site, Sevilleta, New Mexico, to assess whether NRM is likely to be important in regions with rainfall intermediate to the Namib and Iowa, and to test approaches for characterizing NRM decomposition using long-term meteorological records that lack leaf wetness sensor data.

The Namib sites are located in a linear dune system and include an east and west site that differ in rain and fog inputs (Figure 1A). At the Namib East site, rainfall is about $81 \mathrm{~mm}$, and fog is rare (Lancaster and others 1984; Eckardt and others 2013). Dew frequency had not been quantified at the eastern site before this study. At the Namib West site, mean annual rainfall is lower than the eastern site $(19 \mathrm{~mm})$ and variable, and fog and dew are common (each occurring $>50$ nights per year) (Henschel and Seely 2008; Eckardt and others 2013; Jacobson and others 2015). Both Namib sites are dominated by the perennial dunegrass Stipagrostis sabulicola (Figure 1A inset). The Iowa site is in a restored tallgrass prairie near Grinnell, Iowa, USA, with a mean annual rainfall of $897 \mathrm{~mm}$ (ncdc.noaa.gov) (Figure 1B). NRM frequency had not been quantified before this study. Vegetation is dominated by Andropogon gerardii (Figure 1B inset) and a diverse assemblage of prairie forbs. The New Mexico site is a semiarid grassland in the Sevilleta 
National Wildlife Refuge with a mean annual rainfall of $240 \mathrm{~mm}$ (Peters and Yao 2012) (Figure S1, Table 1). NRM frequency had not been quantified before this study. Notably, at this site

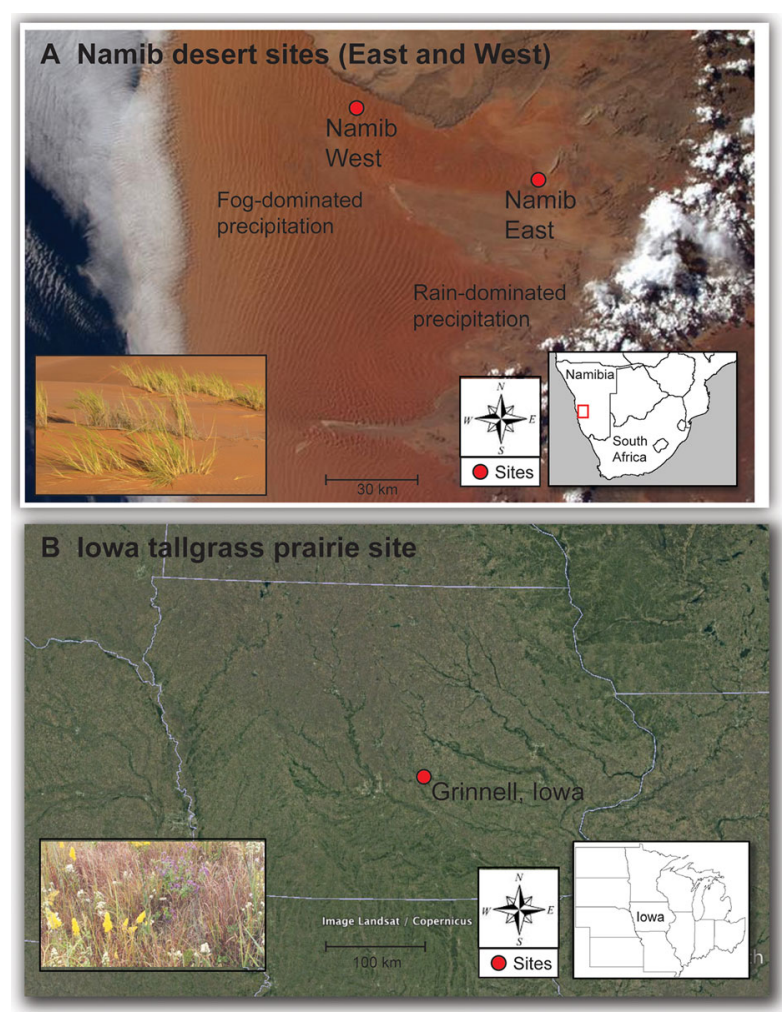

Figure 1. Site descriptions. This study was conducted in: A: the Namib Desert, Namibia, at the NRM-dominated 'Namib West' site and rain-dominated 'Namib East' site. We measured microbial $\mathrm{CO}_{2}-\mathrm{C}$ flux from Stipagrostis sabulicola, the dominant plant (inset). B: Iowa tallgrass prairie in Grinnell, Iowa. We measured litter flux from Andropogon gerardii, the dominant plant. Inset shows diverse mix characteristic of tallgrass prairie.
Vanderbilt and others (2008) found that annual mass loss within a site correlated poorly to annual rainfall, suggesting alternative decomposition mechanisms are at play. We made no empirical measurements at the site, but analyzed NRM frequency from standard meteorological data (http://d igitalrepository.unm.edu/lter_sev_data/8/). Vegetation here is dominated by Bouteloua eriopoda and Bouteloua gracilis.

\section{Meteorological Measurements and Analysis of NRM Frequency Using Leaf Wetness Sensors}

We assessed meteorological conditions at Namib West, Namib East, Iowa, and Sevilleta sites (Table 1), by taking advantage of existing infrastructure and datasets, and adding capabilities where necessary. Namib West is equipped with a SASSCAL meteorological station (http://www.sasscal.or g/), which houses a Campbell CS215-L temperature and humidity probe positioned at $2 \mathrm{~m}$, a Juvik fog collector, and a leaf wetness sensor (Campbell 237-L, uncoated, $10 \mathrm{~cm}$ height). The Juvik fog collector is an omnidirectional, cylindrical aluminum fog screen, positioned at a height of $1.5 \mathrm{~m}$ (Juvik and Nullet 1995), and fitted onto a Young tipping rain gauge (Y52203, Young Company, Michigan, USA). At Namib East, we monitored air temperature and relative humidity ( $\mathrm{RH})$ (height: $150 \mathrm{~cm}$ ), rainfall and leaf wetness (height: $25 \mathrm{~cm}$ ) using a HOBO data logger and sensors (H21-002, STHB-M002, Davis S-RGD-M002, S-LWA-M003) (Onset Computer Corp., USA).

A similar meteorological array was used at the Iowa site, except that the RH and temperature sensors were positioned at a height of $65 \mathrm{~cm}$, which was in the midst of the prairie vegetation. An automated tipping-bucket rain gauge (HOBO, RG3-

Table 1. Site and Meteorological Details for the Four Sites Studied

\begin{tabular}{|c|c|c|c|c|}
\hline & Namib East & Namib West & Iowa & Sevilleta \\
\hline \multirow[t]{2}{*}{ Site coordinates } & S 23.7835 & S 23.5604 & $\mathrm{~N} 41.7568$ & N 34.3592 \\
\hline & E 15.7796 & E 15.0410 & W 92.7151 & W 106.691 \\
\hline Mean annual temperature $\left({ }^{\circ} \mathrm{C}\right)^{+}$ & 23.1 & 21.0 & 8.84 & 13.5 \\
\hline Mean annual rainfall $(\mathrm{mm})^{+}$ & 81 & 19 & 897 & 232 \\
\hline Mean relative humidity $(\%)^{+}$ & 32 & 49 & $69^{ \pm}$ & 40 \\
\hline Met measurement dates ${ }^{ \pm}$ & $6 / 24 / 15-6 / 4 / 16$ & $6 / 15 / 15-6 / 16 / 16$ & $3 / 9 / 16-1 / 6 / 17$ & $1 / 1 / 11-1 / 1 / 16$ \\
\hline Met measurement length (d) & 346 & 367 & 303 & 1825 \\
\hline
\end{tabular}

${ }^{+}$Citation for mean climate variables: Namib West (Lancaster and others 1984; Eckardt and others 2013), Namib East (Henschel and Seely 2008; Eckardt and others 2013; Jacobson and others 2015), Sevilleta (Hochstrasser and others 2002), Iowa (ncdc.noaa.gov, climate station GHCND:USC00133473; https://www.currentresults.com/Weather/ Iowa/humidity-annual.php for relative humidity).

${ }^{ \pm}$Refers to meteorological measurements made in this study, reported in Table 2. 
M, $15.24 \mathrm{~cm}$ diameter, $0.2 \mathrm{~mm}$ resolution) was placed nearby at an elevation of $1.5 \mathrm{~m}$. In Sevilleta, New Mexico, we analyzed NRM frequency from data recorded at the Deep Well Meteorological Station (No. 40), including hourly RH, rainfall, and air temperature. RH and temperature sensors were positioned at a height of $2.5 \mathrm{~m}$. Instrumentation details can be found at http://digitalrepository.un m.edu/lter_sev_data/8/. Leaf wetness data were not recorded at Sevilleta. In sum, meteorological arrays differed slightly across sites. The most important differences were the height of the leaf wetness sensor relative to the plant canopy, and leaf wetness units. We addressed differences in units by converting continuous leaf wetness to categorical when comparing across sites, and sensor height differences by stating in the results when we thought the height of the sensor impacted our findings.

We estimated total wet hours due to NRM at a site by using either (1) the number of hours leaf sensors were wet, (2) the number of hours that exceeded an RH threshold (Sentelhas and others 2008), or (3) a function ('likelihood wet') that estimated the likelihood a sensor would be wet, based on RH. A wet hour was attributed to rain if rainfall was detected during that hour.

Leaf wetness sensors (Figure 2E) have been widely used by plant pathologists to estimate periods of wetness that are independent of rainfall (Rowlandson and others 2015), and in other studies to estimate NRM (Gotsch and others 2014; Gliksman and others 2017) by measuring water droplets and films on electronic grid surfaces. In sensors that measured wetness on a discrete scale (Campbell 237-L, Namib West), the wet-dry transition occurred at about $150 \mathrm{kohm}$; for continuousscale $(\%)$ wetness sensors (Iowa, Namib East), we conservatively defined 'dry' periods as those below $10 \%$ wetness. We estimated wet hours from RH by totaling hours that $\mathrm{RH}$ exceeded either $75 \% \mathrm{RH}$ (low threshold) or $90 \% \mathrm{RH}$ (higher threshold), as informed by previous work (Sentelhas and others 2008). Finally, we determined the relationship between wetness sensor readings and $\mathrm{RH}$ at each site, developing a function ("likelihood wet") for the likelihood that the leaf wetness sensor indicated 'wet' for a given RH. These likelihood curves were remarkably similar across sites (Figure S3), justifying use of the mean curve to estimate the number of hours at each site that the sensor was wet (with an uncertainty band based on the between-site variation), including the Sevilleta site, as derived from RH. This estimate of wet hours was used to extrapolate $\mathrm{CO}_{2}$ loss over time (see last section).

Having defined wet hours (as determined by leaf wetness in Iowa and the Namib Desert, and a likelihood function in Sevilleta), we calculated the mean temperature and humidity associated with NRM and rain within each site during these events. We were also interested in the duration of a typical rain and NRM event, which required that we delineate the start and end to an event. In our analysis, events were initiated by at least 2 wet hours in a row (to exclude spurious wet hours) and ended at the first 2 dry hours detected. Delineation of events was not possible in Iowa because leaf wetness sensors were often continuously wet for weeks at a time, likely due to the location of the sensor within the prairie canopy. Thus, in contrast to the drier sites, many 'events' at the Iowa site could include both rain and NRM. Please see http s://github.com/ktoddbrown/NRM_litter_decay for the code associated with this analysis.

\section{Empirical Measurements of Mass Loss and Respiration in the Field}

We measured litter mass loss using litter racks (Figure 2B) instead of traditional litter bags, which we found can alter NRM (see Supplement for full details justifying this method). We deployed preweighed native coarse tillers $(4-6 \times 90 \mathrm{~mm})$ in these wooden racks at the Namib and Iowa sites at about $0.5 \mathrm{~m}$ height. In the Namib sites, we monitored mass loss of $S$. sabulicola standing litter that was collected after senescence from each site, airdried, and stored at room temperature until rack deployment. In Iowa, A. gerardii was collected in the fall following senescence, dried at $35^{\circ} \mathrm{C}$, and stored at room temperature until rack deployment. After a 1-year deployment in racks mounted on poles at each site, tillers were similarly dried and stored individually in airtight Whirl-Pak bags until weighed. Mean percent mass loss of the tillers $(n=4-10)$ was compared across sites using a oneway ANOVA.

In addition to mass loss, we assessed $\mathrm{CO}_{2}-\mathrm{C}$ flux rates and moisture content of litter under NRM events. We examined 'coarse' (thick tillers, $\sim 5 \mathrm{~mm}$ diameter, used in mass loss studies) as well as 'fine' (stem sheaths and leaves) litter types (Figure 2C) to test whether the effect of NRM differed by substrate (Jacobson and others 2015). Tillers were collected for respiration measurements in the same way they were collected for assessing mass loss (see above). We deployed racks on a tri- 


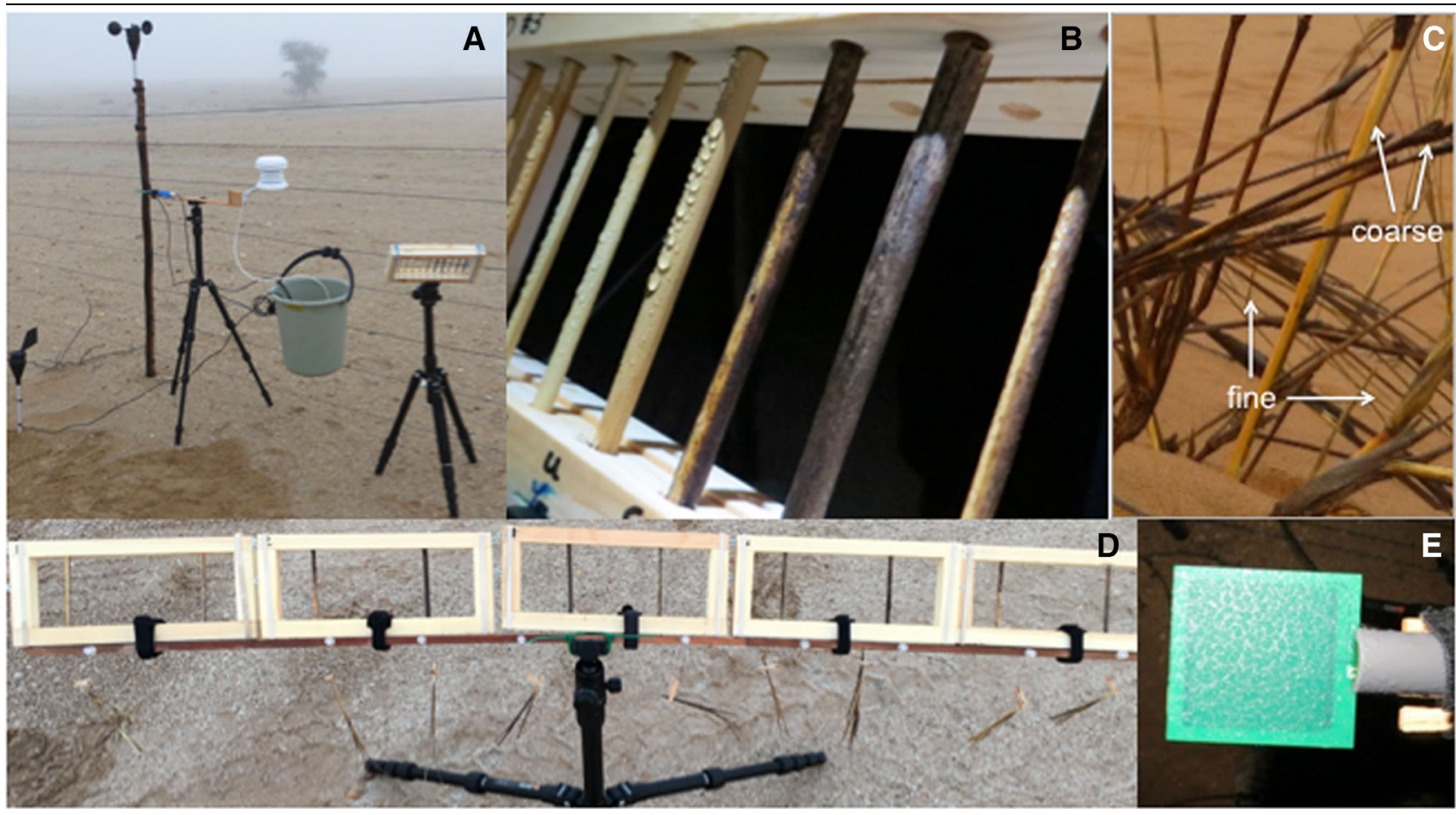

Figure 2. Photographs of standing litter and methodologies. A: Measurement of litter gravimetric moisture and flux in litter rack, and associated portable meteorological station at Namib West. B: Litter rack mimicking standing coarse litter in situ, shown with droplets from NRM. C: Different litter types: fine (leaves) and coarse (tillers, $>2$ mm diameter), shown here on S. sabulicola. D: Fine litter hanging below coarse litter racks during NRM exposure. E: Leaf wetness sensor containing condensed water during an NRM event.

pod in the evening hours, after dark, when climatic conditions suggested an NRM event might occur (Figure 2A, B). We also deployed an autoclaved subset of coarse litter 'controls' to test whether the majority of respiration was microbially mediated or possibly mediated by abiotic mechanisms such as photolysis or thermal emission after sunrise (Lee and others 2012; Day and others 2019). Tillers were kept sterile and in the dark until deployed, but we acknowledge that some respiration on sterile tillers could still be microbial in origin since we could not prevent sterile tillers from being colonized by airborne inoculum during an NRM event (Evans and others 2019). Fine litter $(<1 \mathrm{~mm} \times 4-10 \mathrm{~mm} \times$ $80-120 \mathrm{~mm}$, Figure 2C) was suspended by small clips from a litter stand directly below the racks when an NRM event was anticipated (Figure 2D).

At each measurement time point, we first extracted and weighed individual litter pieces to determine gravimetric moisture content. Then $\mathrm{CO}_{2}-\mathrm{C}$ flux from each tiller was measured over a 3minute period (including a 30-s dead band period) using a Li-8100 $\mathrm{CO}_{2}$ Flux system (LI-COR Inc., Lincoln, NE), equipped with a small $(\sim 55 \mathrm{ml})$ respiration chamber (LI-COR 6400-89). The majority of $\mathrm{CO}_{2}-\mathrm{C}$ flux measurements were taken at night when it was dark and cool (or, after sunrise, at temperatures below $25^{\circ} \mathrm{C}$ and out of direct sunlight) so photolysis and thermal degradation were unlikely or minimal. After measurement, litter pieces were immediately replaced in the rack or stand. At the conclusion of the NRM event, litter was dried at $35^{\circ} \mathrm{C}$ to determine gravimetric moisture, and $\mathrm{CO}_{2}-\mathrm{C}$ flux was expressed on a dry weight basis, as is standard when assessing litter.

We first analyzed whether respiration observed under NRM was microbial in origin by comparing $\mathrm{CO}_{2}$ flux rates of sterilized to unsterilized pieces of litter ( $t$ test, $n=5-10)$. We tested controls for NRM respiration and gravimetric moisture using multiple linear regression. We included all replicate litter pieces in a sampling time point after finding no significant effect of rack $(p>0.1)$ or event $(p>0.1)$, and excluding points at the end of events, which were under-sampled (see Results). With this dataset $(n=128)$, we tested (1) the effect of site, gravimetric moisture, and litter type, on respiration; and (2) the effect of leaf wetness and 
litter type on gravimetric moisture at Iowa and Namib sites. Because $\mathrm{CO}_{2}$ flux at Namib East and West sites did not differ in response to any of these environmental drivers, we combined into one 'Namib' site. All statistical analyses were performed in $\mathrm{R}$ v. 3.4.0 ( $\mathrm{R}$ Core Team 2017).

\section{Extrapolation of $\mathrm{CO}_{2}$ Flux Across Space and Time}

We assumed that microbially mediated decomposition occurred during wet periods at all sites, as supported by our field observations. We used our empirical measurements of gravimetric moisture and litter respiration to determine the $\mathrm{CO}_{2}-\mathrm{C}$ flux associated with a wet hour. We calculated the mean $\mathrm{CO}_{2}-\mathrm{C}$ flux (with $90 \%$ quantiles) when litter was above $15 \%$ gravimetric moisture (an approximate threshold for respiration turning 'on' across sites, see Figure $4 \mathrm{~A}$ ), and estimated $\mathrm{CO}_{2}-\mathrm{C}$ loss at all sites by multiplying this flux rate by estimated wet hours as defined by likelihood wet function (see above for alternative approaches for calculating wet hours that were not used for the $\mathrm{CO}_{2}$ extrapolation). We were unable to directly correct for temperature in our study (for example, using a $\mathrm{Q}_{10}$ sensitivity) and suggest future studies do so. However, we measured $\mathrm{CO}_{2}$ flux under a relatively broad temperature range and captured the resulting variation in respiration rates in the $90 \%$ quantiles, which are used to generate the confidence intervals surrounding our mass loss estimates. We were also not able to connect gravimetric moisture directly to leaf wetness or meteorological conditions (beyond a coarse 'wet/ $\left.d^{\prime} y^{\prime}\right)$ and look forward to future studies addressing this gap. To facilitate comparisons across sites, which had slightly different measurement periods, we converted extrapolated $\mathrm{CO}_{2}$ flux to an annual scale. Although the goal of our study was not to develop models for mass loss, we did measure mass loss in the field at these sites and we wanted to compare our extrapolated estimates that included and excluded NRM to these mass loss values. To do this, we calculated a $\mathrm{CO}_{2}$-flux-based 'extrapolated mass loss', converting $\mathrm{C}$ to litter mass by assuming $50 \%$ of mass was C (Schlesinger 1977), but acknowledge that we did not measure other processes that contribute to mass loss, like leaching of dissolved organic $\mathrm{C}$ or other trace gas loss.

\section{Results \\ Characterization of Non-rainfall Moisture (NRM) Across Sites}

Despite the large difference in rainfall across the sites (Table 1), many aspects of NRM were similar. For instance, the proportion of wet hours attributed to NRM was exceedingly high (85.0-99.1\%), and NRM generally occurred during humid (81-93\%) and cool $\left(12-13^{\circ} \mathrm{C}\right)$ periods for several hours or more (Table 2, Table S3, Figure S2), conditions sufficient to induce microbial activity. We observed substantially more total NRM wet hours compared to rainfall-wet hours at all sites. In the Namib sites, temperature during NRM was generally lower than it was during rain, and $\mathrm{RH}$ was higher (Table 2, Table S2). In Iowa, NRM occurred across a broader range of temperatures than in the Namib (Table 2), and at more similar temperatures to those in rain periods. In addition to their far greater frequency, NRM events may also last longer than rain events (Figure S2), but we could not test this comprehensively because of the few rain events in the Namib sites, and the challenge in delineating events in the Iowa site. Specifically, wetness sensors measured many-day wet periods in Iowa, especially in the summer months, because of the consistently high humidity at the height of the sensor $(65 \mathrm{~cm})$ resulting from the dense vegetation canopy that traps soil-derived moisture. In the Namib, NRM events were longer in Namib West $(7.3 \mathrm{~h})$ than in Namib East $(6.0 \mathrm{~h}) \quad(p=0.007)$ (Figure S2). A general caveat to these trends is that our sampling period was a single year, not longterm mean annual NRM frequency. We have no reason to assume our NRM data are unique to this year and note that annual precipitation means for our sampling periods are similar to or slightly lower than published long-term means at each site (Table 1).

The different approaches for estimating wet hours (wetness sensor, high humidity, and a likelihood function) were generally comparable within a site, and consistently estimated more wet hours due to NRM than wet hours attributed to rain (Figure 3). Estimates of wet hours from leaf wetness sensors fell within the range of estimates generated using RH threshold, but the RH threshold chosen (75\% vs. $90 \%$ ) had a large impact on the proportional contribution of NRM to wet hours in a site (Figure 3). An RH of $85 \%$ produced estimates near those measured by leaf wetness sensors. 
Non-rainfall Moisture: A Key Driver of Microbial Respiration from Standing Litter in Arid, Semiarid, and Mesic Grasslands

Table 2. Summary of Non-rainfall Moisture (NRM) and Rain Across Sites

\begin{tabular}{|c|c|c|c|c|c|c|c|c|}
\hline & \multicolumn{2}{|l|}{ Namib East } & \multicolumn{2}{|c|}{ Namib West } & \multicolumn{2}{|l|}{ Iowa } & \multicolumn{2}{|l|}{ Sevilleta } \\
\hline & NRM & Rain & NRM & Rain & NRM & Rain & $\mathrm{NRM}^{\S}$ & Rain \\
\hline $\begin{array}{l}\text { Rainfall } \\
\qquad(\mathrm{mm})^{ \pm}\end{array}$ & & 67.2 & & 12.2 & & 867.1 & & 198.8 \\
\hline $\begin{array}{c}\text { Total time } \\
\text { wet }(\mathrm{h})\end{array}$ & 391 & 47 & 1508 & 13 & 4918 & 346 & 1039 & 183 \\
\hline $\begin{array}{c}\% \text { of total } \\
\text { hours }\end{array}$ & $4.0 \%$ & $0.5 \%$ & $17.4 \%$ & $0.1 \%$ & $72.3 \%$ & $4.8 \%$ & $11.9 \%$ & $2.1 \%$ \\
\hline $\begin{array}{c}\% \text { of wet } \\
\text { hours }\end{array}$ & $89.2 \%$ & $10.7 \%$ & $99.1 \%$ & $0.9 \%$ & $93.4 \%$ & $6.6 \%$ & $85.0 \%$ & $15.0 \%$ \\
\hline $\begin{array}{l}\text { Mean RH } \\
\quad(\%) \pm \mathrm{SD}^{+}\end{array}$ & $81.1 \pm 11.6$ & $68.0 \pm 19.9$ & $87.7 \pm 9.0$ & $72.8 \pm 8.8$ & $93.5 \pm 7.0$ & $97.9 \pm 5.9$ & $83.6 \pm 9.2$ & $77.0 \pm 17.2$ \\
\hline $\begin{array}{l}\text { Mean tem- } \\
\text { perature } \\
\left({ }^{\circ} \mathrm{C}\right) \pm \mathrm{SD}\end{array}$ & $12.5 \pm 6.6$ & $21.5 \pm 5.3$ & $12.9 \pm 4.0$ & $18.2 \pm 2.5$ & $12.8 \pm 10.1$ & $13.0 \pm 7.6$ & $3.9 \pm 9.5$ & $12.6 \pm 8.5$ \\
\hline
\end{tabular}

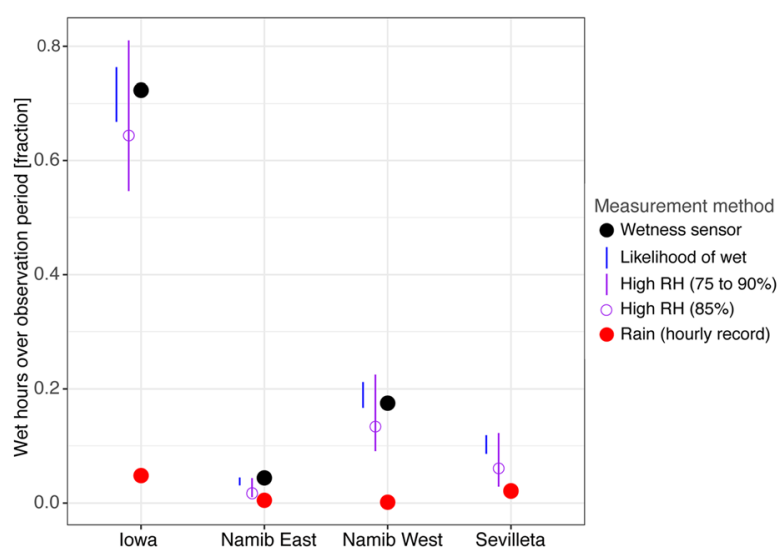

Figure 3. Estimates of the time litter is wet, as a fraction of each site's measurement period (see Table 1), as estimated by different approaches. 'Likelihood of wet' was used to extrapolate mass loss. Red dot: raining time (wet hour was attributed to rain if rainfall was detected during that hour). Black dot: wet hours as estimated by leaf wetness sensors. Blue line: likelihood of a wet sensor ('likelihood wet' function) for a given relative humidity, based on relationships at Iowa and the Namib. Purple line: estimates using $\mathrm{RH}$ threshold, with the lower bound using a threshold of $75 \%$ and upper bound, $90 \%$, and open purple circle showing $85 \%$.

A "likelihood wet" function also produced wet estimates similar to those measured by leaf wetness at each site (Figure S3, Figure 3), which also indicated that our estimates of wetness frequency at
Sevilleta were similar to what we would have measured with a leaf wetness sensor.

\section{Field Measurements of NRM-Induced Microbial Respiration}

We observed significant $\mathrm{CO}_{2}$ release under multiple NRM events from standing litter in both arid and mesic grassland systems (Table S3). In a typical NRM event in the Namib that induced respiration (Figure 4), $\mathrm{CO}_{2}$ flux was typically first detected (that is, above background levels) during the night as temperatures decreased and RH increased. Rates of $\mathrm{CO}_{2}$ flux were sustained with high litter moisture during the nighttime hours and then decreased in the morning as $\mathrm{RH}$ decreased and temperature increased (Figure 4B \& C). Notably, in this event, microbial respiration decreased before litter moisture, but in other events, microbial respiration continued when leaf wetness was 'dry' and moisture was very low (Table S3). $\mathrm{CO}_{2}-\mathrm{C}$ flux rates at a single time point were as high as $109.58 \mu \mathrm{g}$ $\mathrm{CO}_{2}-\mathrm{C} / \mathrm{g}$ litter/hour (mean across $n=5$ pieces of fine litter during fog in Namib West) (Table S3). The majority of $\mathrm{CO}_{2}$ flux was mediated by microbial activity; sterile tillers exposed to NRM had very low $\mathrm{CO}_{2}$ flux rates that were significantly lower than microbial respiration from non-sterile tillers (Table S4). Because it was difficult to predict when dew would occur, we started most $\mathrm{CO}_{2}$ flux measurements in the middle of an event (Figure 4A), so 

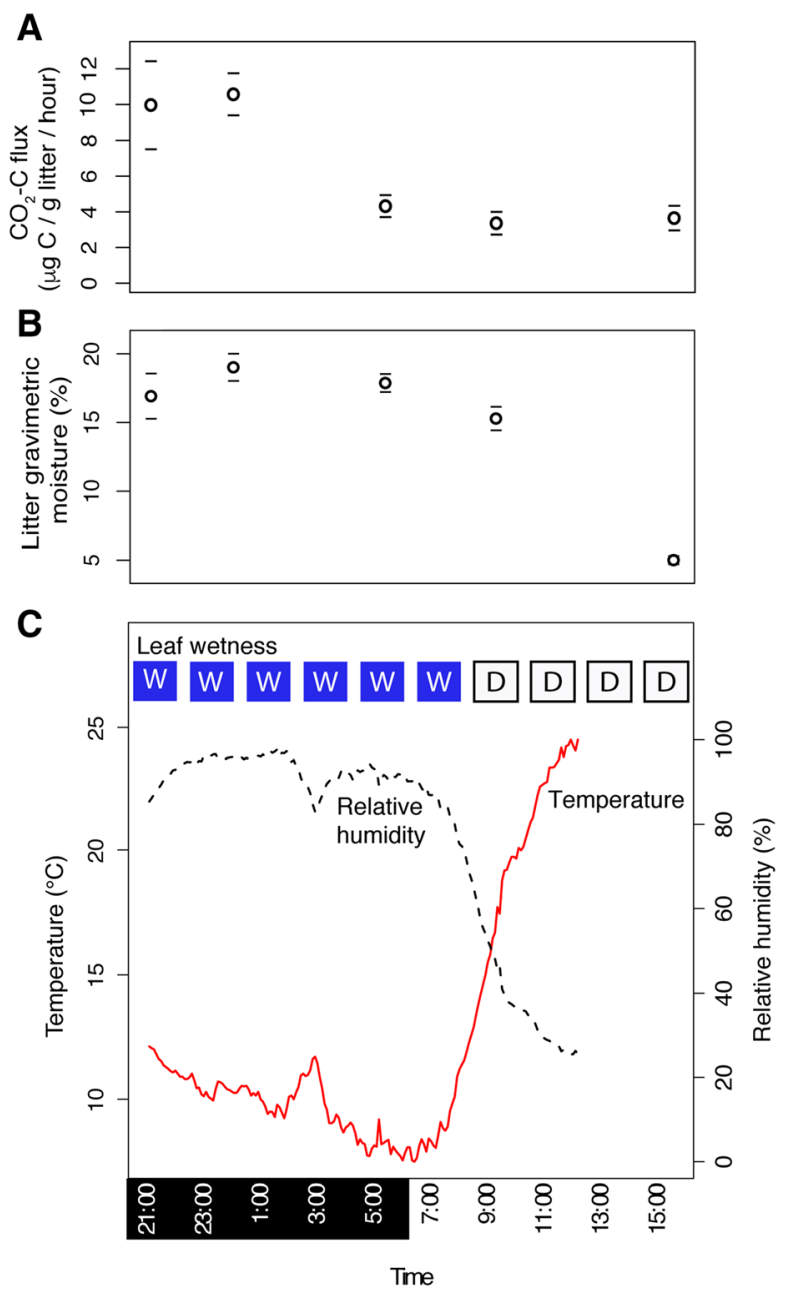

Figure 4. Response of standing S. sabulicola (coarse) litter to one dew event at Namib West on 3 June 2015 (see Table S3 for all events). A: mean $\mathrm{CO}_{2}-\mathrm{C}$ flux rates, measured from coarse litter, B: gravimetric moisture ( $n=10$, dashes represent $1 \mathrm{SE}$ above and below the mean represented by symbols), and C: meteorological parameters over the course of one night ( $\mathrm{W}=$ wet and $\mathrm{D}=$ dry leaf wetness reading). $\mathrm{CO}_{2}-\mathrm{C}$ flux was generally higher from fine litter (Table S3). Dew began around 19:00, when leaf wetness read "slightly wet" and relative humidity was $83 \%$.

we know less about moisture levels that induce respiration under NRM. Events generally ended by mid-morning (09:00) (Figure 4C) but on three occasions we observed tillers that were slightly wet (5-10\% gravimetric moisture) and respiring at low levels into the late morning and early afternoon, even though the leaf wetness sensor measured zero (Table S3, Figure 4).

We used a regression approach to test the generality of the response of respiration to NRM across litter type, site, and precipitation type (rainfall, fog, dew, high humidity) in the Namib and Iowa. Since
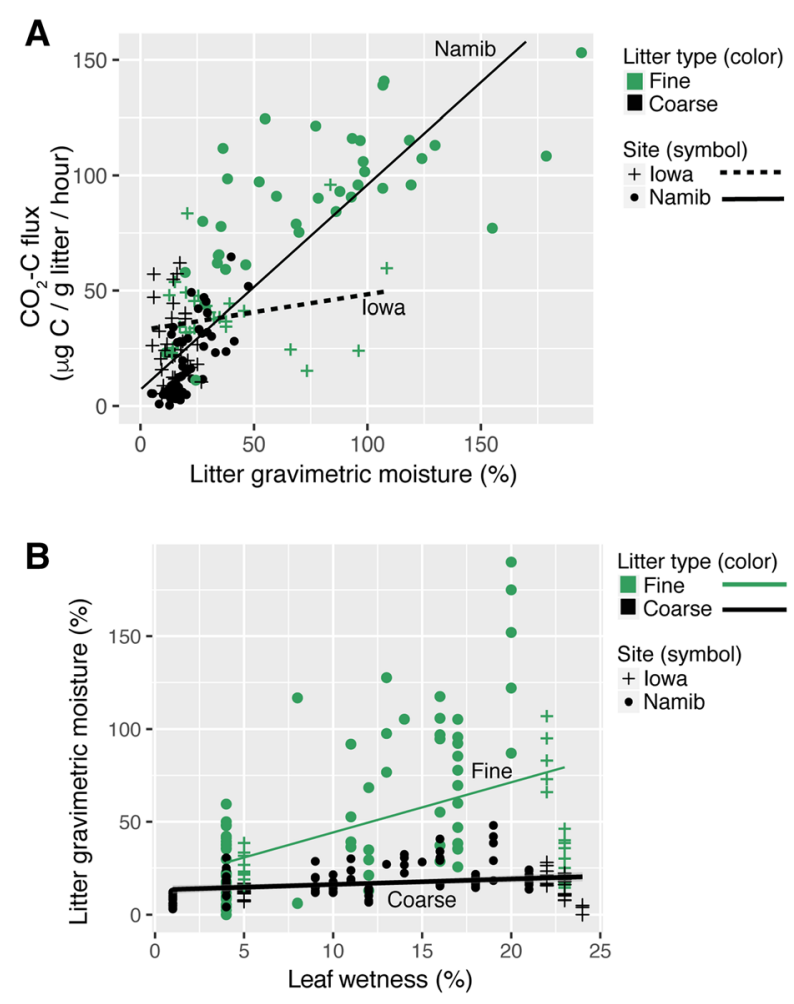

Figure 5. A Under NRM, gravimetric moisture was positively related to $\mathrm{CO}_{2}-\mathrm{C}$ flux for the Namib (combined East and West, $y=0.88 x+7.38, R^{2}=0.71$, $p=0.038)$ and Iowa $\left(y=0.209 x+27.88, R^{2}=0.06\right.$, $p<0.001)$. B Under NRM, gravimetric moisture content of fine litter increased significantly more than that of coarse litter under the same leaf wetness, as measured by leaf wetness sensors (reject null of equal slope, $p=0.01$ ).

we were interested in controls on the maximum and sustained respiration flux, and did not have the sample size to determine the conditions under which respiration ceased, we excluded all $\mathrm{CO}_{2}-\mathrm{C}$ flux measurements that occurred while litter was drying (for example, at the end of an event) from regression analysis (Table S3, right column). NRM induced significant respiration at Namib West (where fog is common), but also at Iowa and Namib East sites (Figure 5, Table S3), verifying that microbial activity under NRM is not unique to sites where fog is frequent, or to hyper-arid systems.

Gravimetric moisture explained $60 \%$ of respiration under NRM across sites $(p<0.001)$ (Figure $5 \mathrm{~A})$, although it explained little variation in Iowa $\left(y=0.209 x+27.88, R^{2}=0.06, p<0.001\right)$, compared to the Namib $(y=0.88 x+7.38$, $R^{2}=0.71, p=0.038$, Figure $\left.5 \mathrm{~A}\right)$. There was no difference in $\mathrm{CO}_{2}-\mathrm{C}$ flux response between the two Namib sites. The slope of respiration response differed between Namib and Iowa sites, however 
( $p<0.05$ to reject the null of equal slopes). $\mathrm{CO}_{2}$ flux measured from fine litter in Iowa was more constrained at the wetter end, but this may be explained by the fact that sampling in Iowa took place during cooler events (mean temperature for fine litter NRM events in Iowa $=8.4^{\circ} \mathrm{C}$ and $\mathrm{Na}$ $\mathrm{mib}=14.9^{\circ} \mathrm{C}$, Table S3), rather than differences in microbial community activity across sites. Litter type significantly affected the extent of litter wet up during NRM $(p<0.001)$. Fine litter (leaves and tiller sheaths, see Figure 2C) became wetter than coarse litter (tillers) under the same leaf wetness (Figure 5B) and generally exhibited higher $\mathrm{CO}_{2}$ flux (Figure 5A).

We also tested whether rain versus NRM events have different effects on litter wetness and $\mathrm{CO}_{2}$ flux. We did not measure flux under rain in enough rain events to assess this statistically, but our data suggest that NRM events result in at least as much wet up and C loss as rain events. During the rain event, we documented in Iowa, mean flux was $28.33 \mu \mathrm{g} \mathrm{CO} \mathrm{CO}_{2}-\mathrm{C} / \mathrm{g}$ litter/hour $(n=5)$, within the range of flux observed under NRM events (0.166$37.91 \mu \mathrm{g} \mathrm{CO}_{2}-\mathrm{C} / \mathrm{g}$ litter/hour, Table S3). During a relatively large rain event at the Namib West site (12.8 mm, 6 June 2016), coarse litter gravimetric moisture was similar to moisture reached under typical NRM events (maximum 32\% under rain, $35 \%$ under NRM), and fine litter actually became more wet under NRM than rain (maximum 20.5\% under rain and $145 \%$ under NRM) (Table S3). We did not discern any differences in moisture or flux patterns between NRM types (fog vs. dew; $p$ value $>0.05, n=5$ dew and $n=3$ fog events).

\section{Contribution of NRM to Annual Decomposition}

Litter mass loss, measured empirically, was highest in Iowa and generally low in the arid and hyperarid Namib sites (Figure 6). Notably, mass loss in the in Namib West was similar to-and even trending higher than-mass loss in Namib East (but not significantly different, $p=0.66)$, a site with more rainfall but less NRM (Table 2, Figure S2). The exclusion of NRM (that is, using rain as the only driver of decomposition) resulted in very low estimates of extrapolated annual mass loss at all sites (Figure 7). Incorporating NRM resulted in a $\sim$ sixfold increase in extrapolated mass loss at the most mesic Iowa site, to a greater than 100-fold increase at the hyper-arid Namib West site (Figure 7). The height of the sensors in Iowa, which were beneath the plant canopy unlike sensors at other sites, may have contributed to the high NRM

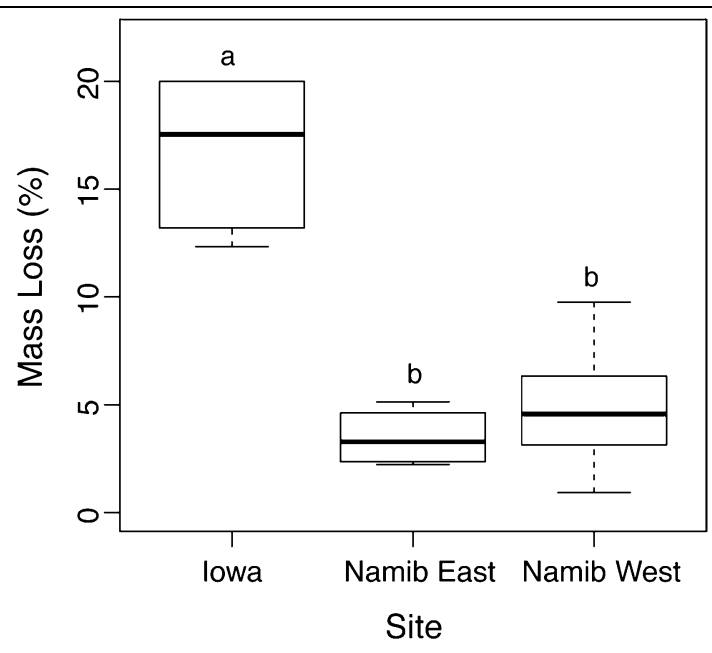

Figure 6. Mass loss of standing litter in mesic (Iowa) and hyper-arid (Namib) sites that had different rain and NRM regimes. Box shows upper and lower quartiles and line within the box represents the median. Litter was native ( $S$. sabulicola in Namib sites, A. gerardii in Iowa) coarse grass 'tillers' deployed in standing litter racks at the height of native standing litter. Different letters represent significant $(p<0.01)$ differences (pairwise $t$ tests) among mean mass loss in Iowa $(n=5,303$ days deployment), Namib East ( $n=5,343$ days), and Namib West $(n=26,344$ days $)$.

measured in Iowa because plant transpiration leads to high RH. Using rainfall hours alone underestimated observed mass loss in the sites where it was measured (Namib and Iowa, lines, Figure 7, standardized to annual scale), whereas NRM + Rainextrapolated estimates fell within the range of observed values. This is true even though extrapolation calculations did not include photodegradation (photolysis or photopriming) but rather based on respiration rates made on litter stored in the dark and assessed at night. This omission (or other assumptions in the extrapolation) could have contributed to underestimation of observed mass loss at high-UV sites like Namib East. At Sevilleta, when NRM was included, extrapolated mass loss was closer to observed values, which previous studies have estimated to be $10 \%$ for $A$. gerardii (Brandt and others 2010) and $20.1 \%$ for B. eriopoda (Vanderbilt and others 2008). We took caution in using these values as comparison because they were determined by litterbags, which could underestimate observed NRM decomposition (see Supplemental Methods).

Estimates of extrapolated mass loss that included NRM had large confidence intervals (Figure 7). The primary source of this uncertainty was the wide range of potential $\mathrm{CO}_{2}$ flux rates that can be in- 


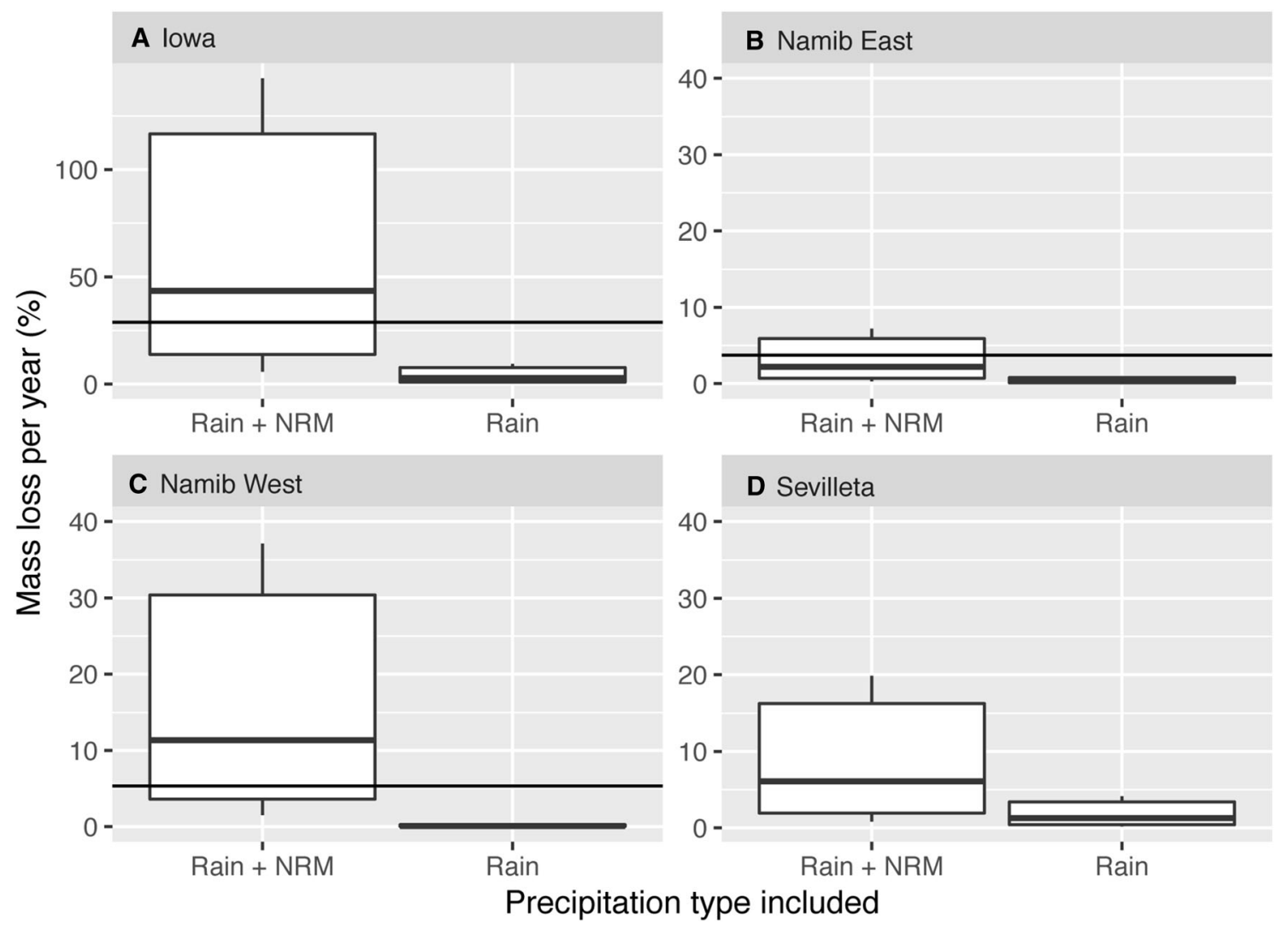

Figure 7. Model-extrapolated litter mass loss when NRM decomposition is excluded ("Rain") and included ("Rain + NRM"). Wet hours were defined by wetness likelihood function for all sites, and 95\% confidence intervals include uncertainty generated from variation in respiration data and wetness duration estimates (see Figure S4 for uncertainty separated). Black solid lines show observed mean mass loss at each site (not measured at Sevilleta), standardized to an annual scale to facilitate comparison.

duced under wet conditions (refer to data in Figure 5), rather than uncertainty surrounding the estimations or extrapolation of NRM duration (Figure S4). Even when NRM duration was directly measured using leaf wetness sensors, removing the uncertainty introduced by duration estimates, confidence intervals for the overall $\mathrm{CO}_{2}$ flux rates remained large (Figure S4C). Still, other factors did introduce some variation in estimated NRM duration. There were some differences in the relationship between leaf wetness and RH at different sites; for example, sensors became wet at slightly lower RH values at Namib East than at Namib West (Figure S3). The global RH function predicting leaf wetness (Figure S3) was also in line with previous estimates; predicted sensors were more likely to be wet than dry around $82 \%$ RH. Finally, as noted above, we also examined the accuracy of estimating wet days using an RH threshold approach. Although we did not use this approach for our primary extrapolation of mass loss (in Figure 7), we did find that the RH threshold chosen is extremely important. Decomposition estimates were very sensitive to the threshold value chosen $(75-90 \%$ in this study, Figure 3 and Figure S4), reiterating the need for site-specific calibrations of wetness sensorRH relationships. A well-chosen threshold would probably generate similar estimates as the $\mathrm{RH}-$ wetness relationship that we could generate with our leaf wetness data.

\section{Discussion}

NRM Contributes to Annual Mass Loss of Standing Litter Across Grassland Types

Our empirical measurements demonstrated that NRM (fog, dew, high humidity) is an important, year-round driver of standing litter decomposition in sites representing distinct grassland systems and that NRM events that induce microbial activity are frequent in semiarid grasslands as well. We estimated that in all sites, $85-99 \%$ of wet hours were 
attributable to NRM, and as informed by on-theground respiration measurements, NRM was a large contributor to annual decomposition of standing litter at all sites-greater than that of rainfall. Our goal was not to produce a predictive decomposition model-this will require larger empirical datasets, and incorporation of other factors like temperature. Still, our first effort to scale contributions of NRM does show that including NRM produced values much closer to measured mass loss. Our extrapolation was imperfect because it is based only on losses from $\mathrm{CO}_{2}-\mathrm{C}$ flux, but it demonstrates what many other studies have suggested (Dirks and others 2010; Jacobson and others 2015; McHugh and others 2015; Gliksman and others 2017): That NRM is not just a fleeting stimulator of occasional heterotrophic $\mathrm{CO}_{2}$ flux, but rather an important driver of surface litter decomposition on an annual scale, in many grassland types.

In dryland sites, many decomposition models that use rainfall as the sole moisture source underestimate empirical observations of litter mass loss (Parton and others 2007; Adair and others 2008; Brandt and others 2010; Currie and others 2010), even though it is an important predictor of mass loss in more mesic systems. Our study suggests that exclusion of NRM from models could contribute to this underestimation. This is first highlighted by our empirical measurements: 1 year of mass loss in a site with almost no rain but high NRM (Namib West) had slightly higher mass loss than another site with higher rainfall but lower NRM (Namib East). Furthermore, mass loss estimates were substantially closer to observed values when NRM was included in our model extrapolation. Other mechanisms, in particular photodegradation, are also likely to be important in dryland decomposition, and have improved model predictions of dryland decomposition (Brandt and others 2010; Adair and others 2017). Photodegradation may be an especially important stimulator of decomposition when it interacts with-and facilitates-microbial decomposition (Foereid and others 2010; Gliksman and others 2017; Day and others 2018); in fact, the contribution of high-UV periods to decomposition may be negligible without intermittent, microbially active wet periods (Lin and others 2018), at least as long as the system is generally moisture limited (Smith and others 2010). Our study shows that NRM could provide these wet periods that induce microbial activity, as suggested by Jacobson and others (2015) and Gliksman and others (2017). We found that NRM delivers these essential wet periods on a diel scale and contributes more wet hours for microbial activity than rainfall, which may not be the best indicator of water availability.

NRM was also the primary contributor to wet periods in our mesic grassland site $193 \%$ of total wet hours), highlighting the ubiquity of NRM-induced wetness across grassland systems. A recent analysis of dew frequency across the USA also demonstrated that dew frequency is high (occurring in up to $95 \%$ of nights) and variable in grasslands, and dependent on nighttime humidity (Ritter and others 2019). We found that excluding periods of NRM in our rain-only model resulted in mass loss estimates much lower than observed values, which is seemingly at odds with the relatively good performance of traditional (rain-driven) decomposition models in mesic grasslands (Parton and others 2007; Adair and others 2008). We suspect that this is because relative humidity $(\mathrm{RH})$ is included in many traditional models, thus implicitly allowing NRM to influence water availability in soils and litter (that is, Parton and others (2001)), whereas our rain-only extrapolation did not. An implicit approach might be sufficient to predict RHinduced wetness that is due to retention of moisture (through reduced evapotranspiration) in the soil-grass canopy system. However, this approach would not capture NRM decomposition resulting from shorter-term (for example, diel) RH fluctuations, which are frequent in xeric systems.

\section{Controls on NRM Decomposition of Surface Litter}

Our empirical measurements of NRM-induced respiration in the field show that moisture thresholds under NRM are similar to those observed in previous studies and in the laboratory. Respiration 'turned on' under NRM around 13-20\% gravimetric moisture, depending on litter type, which narrows our previous estimates $(10.5-30 \%)$, and is remarkably close to minimum thresholds for initiation of litter respiration reported in previous laboratory studies (10-20\%) (Bartholomew and Norman 1947; Nagy and Macauley 1982) and under high humidity in the field $(10 \%)$ (Gliksman and others 2017). Thresholds for initiating versus ceasing respiration may differ due to physical properties of the litter (for example, coarse tillers vs. fine litter), physiological controls on microbial community resuscitation and desiccation, or how litter wets and dries relative to the distribution of microbial biomass, which changes as litter ages (unpublished data, Logan and others). We did not have sufficient replication to fully describe the 
progression of moisture and microbial dynamics over a single NRM event, but we observed periods when microbial activity was decoupled from litter moisture, suggesting measurements over single events are needed.

Our findings reiterate that NRM frequently induces moisture levels sufficient for microbial activity, and standing litter will respire when sufficiently moist, no matter if from rain or NRM. $\mathrm{CO}_{2}$ flux rates measured from litter were primarily driven by gravimetric moisture, but response was also modulated by other factors, like litter type. Finer portions of litter reached higher wetness and exhibited higher $\mathrm{CO}_{2}$ flux, compared to coarse tillers under the same conditions, corroborating previous laboratory measurements (Jacobson and others 2015). Differences in moisture absorbance are likely due to differences in surface area-tovolume ratio or to physical properties; for example, the waxy cuticle on coarse stems resists moisture uptake, while fine litter absorbs it readily. High proportions of fine litter could thus cause NRM to have a greater impact on decomposition. In the Namib, fine litter constituted roughly $50 \%$ of $S$. sabulicola standing litter (unpublished data), but this proportion could be higher in systems dominated by annual grasses. Substrate has been known to be have a strong influence on dew formation (Beysens 1995), and early studies recognized that litter type influenced the RH at which litter becomes wet (Bartholomew and Norman 1947). However, physical properties are an under-recognized modulator of decomposition compared to chemical properties like $\mathrm{C} / \mathrm{N}$ and may be especially important for decay of standing litter under NRM. In general, an important goal for future work will be to link standard meteorological descriptors of NRM to litter moisture content. The wide range of moisture contents that litter achieved under NRM drove high variation in $\mathrm{CO}_{2}$ flux. Since we were unable to link NRM meteorological variables directly to moisture content, we were left with greater uncertainty in our modeled mass loss estimates (Figure 7, Figure S4).

Going forward, NRM event duration (for example, number of hours wet) will be an essential variable for estimating the contribution of NRM to decomposition at any site. Unlike rainfall-induced activity, NRM-induced wetness is not easily captured by water amount or yield. Dawson and Goldsmith (2018) recently estimated the contributions of rain to leaf wetness, and Ritter and others (2019) estimated dew from a network of radiometers, but in general quantifications of wet periods stimulated by all forms of NRM-fog, dew, and high relative humidity-are lacking. We found that leaf wetness sensors accurately recorded most NRM events, but could underestimate NRM decomposition because litter can be wet and respiring for longer than sensors read 'wet'. Placement of any sensor at the height of the litter of interest will be essential, as reiterated by the recent analysis of dew (Ritter and others 2019). Ideally, any effort to quantify decomposition-relevant NRM at a site would start with simultaneous measurements of hourly RH, leaf wetness (each at the height of the litter of interest (Sentelhas and others 2008)), and litter gravimetric moisture, potentially taking advantage of novel methods (Wang and others 2015). These data could serve to calibrate estimates of NRM to identify events likely to induce decomposition, and also to estimate wet hours from leaf wetness or RH in past (or to-be-collected) standard meteorological data. With no previous knowledge of these relationships at a site, our data suggest that assuming wet hours occur above a threshold of $85 \% \mathrm{RH}$, which is also a measured threshold for fungal activity (Dix and Webster 1995), can be a good starting point for estimating NRM.

We found that NRM events also correspond to particular meteorological conditions that may need to be accounted for as we determine the cumulative contribution of these periods to annual mass loss. For instance, NRM occurs at lower temperatures than rain events in dry sites (Table 2), in line with the relatively lower water-holding capacity of cooler air. Previous investigations of microbes in drylands focus on traits allowing survival at extremely high temperatures (Sterflinger and others 2012), but many of these organisms have broad thermal optima (for example, Sterflinger and others 2012; Jacobson and others 2015), and may actually be more active during cool moist NRM periods (Jacobson and others 2015). From a modeling perspective, even though NRM decomposition might respond to temperature and moisture in a similar way to rainfall-mediated decomposition, because NRM consistently occurs at cooler temperatures, it might induce lower hourly microbial respiration. Future studies of microbial traits that influence rain and NRM decomposition should examine activity at temperatures relevant to these events, rather than the thermal extremes during which microbes are desiccated and inactive.

\section{Broader Role of NRM in Ecosystems}

The ecological effects of NRM decomposition could extend far beyond decomposition of surface litter during NRM periods, as we documented here. In 
drylands, nighttime NRM may be a key component that alternates with daytime photodegradation to induce greater decomposition than these processes contribute individually (Almagro and others 2015; Gliksman and others 2017; Lin and others 2018). NRM and UV-PAR can also contribute to surface priming in standing litter (Wang and others 2017a), and the resulting leaching of DOC can contribute to soil carbon dynamics (Campbell and others 2016). Finally, we previously showed that NRM decomposition increased surface nitrogen content in grass litter twofold and that termites preferentially consumed this litter (Jacobson and others 2015). Termites and other detritivores are essential prey for higher trophic levels in most arid ecosystems (Crawford and Seely 1995). The importance of NRM-mediated decomposition may cascade through trophic levels independent of the effects of rainfall on subsurface decomposition.

Even more broadly, additional studies are needed to understand the differential effect of NRM on carbon sources and sinks, particularly in grasslands, where surface litter may comprise more than twothirds of annual net primary production (Polis 1991). In addition to litter decomposer communities, NRM can also stimulate surface soil crusts, lichen fields, and hypoliths (Wang and others 2017b), plant growth (Dawson and Goldsmith 2018), and soil microbial activity (Carbone and others 2011). In the Namib, NRM stimulates the growth of perennial bunch grasses as it drips from aboveground structures to shallow roots (Ebner and others 2011), and nutrients leached via these moisture droplets could be recycled to growing plant material and contribute to nutrient islands (for example, Abrams and others 1997). NRM may also influence these processes as it alters the timing of moisture availability, an important regulator of biogeochemical dynamics in grasslands (Jacobson and Jacobson 1998; Austin and others 2004; Borken and Matzner 2009), but one in which NRM is not currently considered.

Accurately predicting carbon dynamics worldwide relies on an improved understanding of the drivers of decomposition processes. We demonstrated that NRM is an important component of decomposition of surface litter in hyper-arid and mesic grasslands, and our first effort to model NRM highlights the complexities involved in using this component to improve mass loss predictions. In future decades, the frequency and duration of fog, dew, and RH are predicted to shift (Haensler and others 2011; Engelbrecht and others 2015; To- maszkiewicz and others 2016), and may already be changing. Takle (2011) reports that Iowa has experienced an increase in summer dew-point temperature over the last several decades, yielding an increase in atmospheric water vapor over the period. Additional monitoring is needed to assess shifts in NRM. Notably, changes in fog and dew patterns may be distinct from one another (for example, in the Namib, Kaseke and others 2017; Wang and others 2017b), and from shifts in rainfall. Our study shows-with empirical evidence and extrapolation-that shifts in both rain and NRM will need to be accounted for to accurately predict future decomposition rates.

\section{ACKNOWLEDGEMENTS}

We thank Robert Logan for insightful discussions and field assistance and Robert and Esbeiry Cordova-Ortiz for helpful comments on the manuscript. We also thank Gobabeb Research and Training Centre and Roland Vogt for meteorological insight and data acquisition. We thank two anonymous reviewers in a previous submission of this manuscript to Ecosystems. Samples were collected under Namibia Ministry of Environment and Tourism research/collecting Permit No. 2228/2016. $\mathrm{PJ}$ and KJ received funding from Grinnell College and SE from Michigan State University and National Geographic Society (WW440-16 to SE). KTB is grateful for the support of the Linus Pauling Distinguished Postdoctoral Fellowship program, part of the Laboratory Directed Research and Development Program at Pacific Northwest National Laboratory, a multiprogram national laboratory operated by Battelle for the US Department of Energy. This is Kellogg Biological Station Contribution No. 2128.

\section{OPEN ACCESS}

This article is distributed under the terms of the Creative Commons Attribution 4.0 International License (http://creativecommons.org/licenses/by/4 $.0 /$ ), which permits unrestricted use, distribution, and reproduction in any medium, provided you give appropriate credit to the original author(s) and the source, provide a link to the Creative Commons license, and indicate if changes were made.

\section{DATA AVAILABILITY}

Current data and code stored at: https://github.c om/ktoddbrown/NRM_litter_decay 


\section{REFERENCES}

Abrams MM, Jacobson PJ, Jacobson KM, Seely MK. 1997. Survey of soil chemical properties across a landscape in the Namib Desert. J Arid Environ 35:29-38.

Adair EC, Parton WJ, Del Grosso SJ, Silver WL, Harmon ME, Hall SA, Burke IC, Hart SC. 2008. Simple three-pool model accurately describes patterns of long-term litter decomposition in diverse climates. Glob Change Biol 14:2636-60.

Adair EC, Parton WJ, King JY, Brandt LA, Lin Y. 2017. Accounting for photodegradation dramatically improves prediction of carbon losses in dryland systems. Ecosphere 8:e01892.

Almagro M, Maestre FT, Martínez-López J, Valencia E, Rey A. 2015. Climate change may reduce litter decomposition while enhancing the contribution of photodegradation in dry perennial Mediterranean grasslands. Soil Biol Biochem 90:214-23.

Austin AT, Vivanco L. 2006. Plant litter decomposition in a semiarid ecosystem controlled by photodegradation. Nature 442:555-8.

Austin AT, Yahdjian L, Stark JM, Belnap J, Porporato A, Norton U, Ravetta D, Schaeffer SM. 2004. Water pulses and biogeochemical cycles in arid and semiarid ecosystems. Oecologia 141:221-35.

Baker NR, Allison SD, Frey SD. 2015. Ultraviolet photodegradation facilitates microbial litter decomposition in a Mediterranean climate. Ecology 96:1994-2003.

Barnes PW, Throop HL, Hewins DB, Abbene ML, Archer SR. 2011. Soil coverage reduces photodegradation and promotes the development of soil-microbial films on dryland leaf litter. Ecosystems 15:311-21.

Bartholomew WV, Norman AG. 1947. The threshold moisture content for active decomposition of some mature plant materials. Soil Sci Soc Proc 11:270-9.

Beysens D. 1995. The formation of dew. Atmos Res 39:215-37.

Borken W, Matzner E. 2009. Reappraisal of drying and wetting effects on $\mathrm{C}$ and $\mathrm{N}$ mineralization and fluxes in soils. Glob Change Biol 15:808-24.

Brandt L, King JY, Hobbie SE, Milchunas DG, Sinsabaugh RL. 2010. The Role of Photodegradation in Surface Litter Decomposition Across a Grassland Ecosystem Precipitation Gradient. Ecosystems 13:765-81.

Campbell EE, Parton WJ, Soong JL, Paustian K, Hobbs NT, Cotrufo MF. 2016. Using litter chemistry controls on microbial processes to partition litter carbon fluxes with the Litter Decomposition and Leaching (LIDEL) model. Soil Biol Biochem 100:160-74.

Carbone MS, Still CJ, Ambrose AR, Dawson TE, Williams AP, Boot CM, Schaeffer SM, Schimel JP. 2011. Seasonal and episodic moisture controls on plant and microbial contributions to soil respiration. Oecologia 167:265-78.

Crawford CS, Seely MK. 1995. Detritus mass loss in the Namib Desert dunefield: influence of termites, gerbils and exposure to surface conditions. J Afr Zool 108:49-54.

Currie WS, Harmon ME, Burke IC, Hart SC, Parton WJ, Silver W. 2010. Cross-biome transplants of plant litter show decomposition models extend to a broader climatic range but lose predictability at the decadal time scale. Glob Change Biol 16:1744-61.

Dawson TE, Goldsmith GR. 2018. The value of wet leaves. New Phytol 219:1156-69.
Day TA, Bliss MS, Placek SK, Tomes AR, Guénon R. 2019. Thermal abiotic emission of $\mathrm{CO}_{2}$ and $\mathrm{CH}_{4}$ from leaf litter and its significance in a photodegradation assessment. Ecosphere 10:e2745.

Day TA, Bliss MS, Tomes AR, Ruhland CT, Guénon R. 2018. Desert leaf litter decay: coupling of microbial respiration, water-soluble fractions and photodegradation. Glob Change Biol 24:5454-70.

Dirks I, Navon Y, Kanas D, Dumbur R, Grünzweig JM. 2010. Atmospheric water vapor as driver of litter decomposition in Mediterranean shrubland and grassland during rainless seasons. Glob Change Biol 16:2799-812.

Dix N, Webster J. 1995. Fungal ecology. London: Chapman $\delta$ Hall.

Ebner M, Miranda T, Roth-Nebelsick A. 2011. Efficient fog harvesting by Stipagrostis sabulicola (Namib dune bushman grass). J Arid Environ 75:524-31.

Eckardt FD, Soderberg K, Coop LJ, Muller A, Vickery KJ, Grandin RD, Jack C, Kapalanga TS, Henschel J. 2013. The nature of moisture at Gobabeb, in the central Namib Desert. J Arid Environ 93:7-19.

Engelbrecht F, Adegoke J, Bopape M, Naidoo M, Garland R, Thatcher M, McGregor J, Katzfey J, Werner M, Ichoku C, Batebe C. 2015. Projections of rapidly rising temperatures over Africa under low mitigation. Environ Res Lett 10:085004.

Evans SE, Dueker ME, Logan JR, Weathers KC. 2019. The biology of fog: results from coastal Maine and Namib Desert reveal common drivers of fog microbial composition. Sci Total Environ 647:1547-56.

Foereid B, Bellarby J, Meier-Augenstein W, Kemp H. 2010. Does light exposure make plant litter more degradable? Plant Soil 333:275-85.

Gallo ME, Sinsabaugh RL, Cabaniss SE. 2006. The role of ultraviolet radiation in litter decomposition in arid ecosystems. Appl Soil Ecol 34:82-91.

Gliksman D, Navon Y, Dumbur R, Grunzweig JM. 2018. Higher rates of decomposition in standing vs. surface litter in a Mediterranean ecosystem during the dry and the wet seasons. Plant Soil 428:427-39.

Gliksman D, Rey A, Seligmann R, Dumbur R, Sperling O, Navon Y, Haenel S, De Angelis P, Arnone JA, Gruenzweig JM. 2017. Biotic degradation at night, abiotic degradation at day: positive feedbacks on litter decomposition in drylands. Glob Change Biol 23:1-11.

Gotsch SG, Asbjornsen H, Holwerda F, Goldsmith GR, Weintraub AE, Dawson TE. 2014. Foggy days and dry nights determine crown-level water balance in a seasonal tropical montane cloud forest. Plant Cell Environ 37:261-72.

Haensler A, Cermak J, Hagemann S, Jacob D. 2011. Will the southern African west coast fog be affected by future climate change? Results of an initial fog projection using a regional climate model. Erdkunde 65:261-75.

Henschel JR, Seely MK. 2008. Ecophysiology of atmospheric moisture in the Namib Desert. Atmos Res 87:362-8.

Hochstrasser T, Kroel-Dulay G, Peters DPC, Gosz JR. 2002. Vegetation and Climate Characteristics of and Semi-Arid Grasslands in North America and Their Biome Transition Zone. J Arid Environ 51:55-78.

Jacobson K, Van Diepeningen A, Evans S, Fritts R, Gemmel P, Marsho C, Seely M, Wenndt A, Yang X, Jacobson P. 2015. Non-rainfall moisture activates fungal decomposition of surface litter in the Namib Sand Sea. PLoS ONE 10:e0126977. 
Jacobson KM, Jacobson PJ. 1998. Rainfall regulates decomposition of buried cellulose in the Namib Desert. J Arid Environ 38:571-83.

Juvik JO, Nullet D. 1995. Comments on "A Proposed Standard Fog Collector for Use in High-Elevation Regions". J Appl Meteorol 34:2108-10.

Kaseke KF, Wang L, Seely MK. 2017. Nonrainfall water origins and formation mechanisms. Sci Adv 3:1-9.

King JY, Brandt LA, Adair EC. 2012. Shedding light on plant litter decomposition: advances, implications and new directions in understanding the role of photodegradation. Biogeochemistry 111:57-81.

Kuehn KA, Steiner D, Gessner MO. 2004. Diel mineralization patterns of standing-dead plant litter: implications for $\mathrm{CO}_{2}$ flux from wetlands. Ecology 85:2504-18.

Lancaster J, Lancaster N, Seely MK. 1984. Climate of the central Namib Desert. Modoqua 14:5-61.

Lee H, Rahn T, Throop H. 2012. An accounting of C-based trace gas release during abiotic plant litter degradation. Glob Change Biol 18:1185-95.

Lin Y, Karlen SD, Ralph J, King JY. 2018. Short-term facilitation of microbial litter decomposition by ultraviolet radiation. Sci Total Environ 615:838-48.

McHugh T, Morrissey EM, Reed SC, Hungate B, Schwartz E. 2015. Water from air: an overlooked source of moisture in arid and semiarid regions. Sci Rep 5:13767.

Nagy LA, Macauley BJ. 1982. Eucalyptus leaf-litter decomposition: effects of relative humidity and substrate moisture content. Soil Biol Biochem 14:233-6.

Newell SY, Fallon RD, Cal Rodriguez RM, Groene LC. 1985. Influence of rain, tidal wetting and relative humidity on release of carbon dioxide by standing-dead salt-marsh plants. Oecologia 68:73-9.

Parton W, Morgan JA, Kelly RH, Ojima DS. 2001. Modeling soil $\mathrm{C}$ responses to environmental change in grassland systems. In: Follett R, Kimble J, Lal R, Eds. The potential of US grazing lands to sequester carbon and mitigate the greenhouse effect. London: CRC Press. p 371-98.

Parton W, Silver WL, Burke IC, Grassens L, Harmon ME, Currie WS, King JY, Adair EC, Brandt LA, Hart SC, Fasth B. 2007. Global-scale similarities in nitrogen release patterns during long-term decomposition. Science 315:361-4.

Peters DP, Yao J. 2012. Long-term experimental loss of foundation species: consequences for dynamics at ecotones across heterogeneous landscapes. Ecosphere 3:art27-3.

Polis G. 1991. Foodwebs in desert communities: complexity via diversity and omnivory. In: The ecology of desert communities. Tuscon: University of Arizona Press. pp 383-438.

R Core Team. 2017. R: a language and environment for statistical computing. Vienna: R Foundation for Statistical Computing.

Ritter F, Berkelhammer M, Beysens D. 2019. Dew frequency across the US from a network of in situ radiometers. Hydrol Earth Syst Sci 23:1179-97.
Rowlandson T, Gleason M, Sentelhas P, Gillespie T, Thomas C, Hornbuckle B. 2015. Reconsidering leaf wetness duration determination for plant disease management. Plant Dis 99:310-19.

Schlesinger WH. 1977. Carbon balance in terrestrial detritus. Annu Rev Ecol Syst 8:51-81.

Schlesinger WH, Andrews JA. 2000. Soil respiration and the global carbon cycle. Biogeochemistry 48:7-20.

Sentelhas PC, Dalla Marta A, Orlandini S, Santos EA, Gillespie TJ, Gleason ML. 2008. Suitability of relative humidity as an estimator of leaf wetness duration. Agric For Meteorol 148:392-400.

Smith WK, Gao W, Steltzer H, Wallenstein MD, Tree R. 2010. Moisture availability influences the effect of ultraviolet-B radiation on leaf litter decomposition. Glob Change Biol 16:484-95.

Sterflinger K, Tesei D, Zakharova K. 2012. Fungi in hot and cold deserts with particular reference to microcolonial fungi. Fungal Ecology 5:453-62.

Takle ES. 2011. Climate Changes in Iowa. In: Cruse R, Jackson LL, Mutel CF, Rogovska NP, Swenson D, Takle ES, Baer N, Brees A, Grayson R, Sharp K, editors. Climate change impacts on Iowa 2010 policy recommendations: report to the governor and the Iowa General Assembly. pp 1-33.

Throop HL, Archer SR. 2009. Resolving the dryland decomposition conundrum: some new perspectives on potential drivers. In: Progress in botany. pp 171-94.

Tomaszkiewicz M, Abou Najm M, Beysens D, Alameddine I, Bou Zeid E, El-Fadel M. 2016. Projected climate change impacts upon dew yield in the Mediterranean basin. Sci Total Environ 566-567:1339-48.

Uclés O, Villagarcía L, Cantón Y, Domingo F. 2016. Partitioning of non rainfall water input regulated by soil cover type. CATENA 139:265-70.

Vanderbilt KL, White CS, Hopkins O, Craig JA. 2008. Aboveground decomposition in arid environments: results of a longterm study in central New Mexico. J Arid Environ 72:696709.

Wang J, Liu L, Wang X, Yang S, Zhang B, Li P, Qiao C, Deng M, Liu W. 2017a. High night-time humidity and dissolved organic carbon content support rapid decomposition of standing litter in a semi-arid landscape. Funct Ecol 31:1659-68.

Wang L, Kaseke KF, Seely MK. 2017b. Effects of non-rainfall water inputs on ecosystem functions. 4.

Wang L, Throop HL, Gill T. 2015. A novel method to continuously monitor litter moisture-a microcosm-based experiment. J Arid Environ 115:10-13.

Whitford W, Meentemeyer V, Seastedt T. 1981. Exceptions to the AET model: deserts and clear-cut forest. Ecology 62:275-7. 